\title{
In Situ TEM Studies of Lithiation/de-lithiation in Chemically-complex Alloys
}

Mahmoud Tamadoni-Saray and Reza Shahbazian-Yassar

University of Illinois at Chicago, Chicago, Illinois, United States

Ever growing demand for high capacity, energy density and stable energy storage devices has grabbed intense attention in materials science research area especially emerging field of high entropy materials (HEMs) toward developing novel and advanced electrode materials to boost next-generation Li-ion batteries performance. Chemically-complex alloys and oxides have attracted more interest since 2015 and mostly on five-component equimolar compositions [1-3]. Here we extend this concept to compositionally complex (non-equimolar) oxides and introduced new solid solution transition-metal-based ( $\mathrm{Fe}, \mathrm{Cu}, \mathrm{Mg}, \mathrm{Mn}, \mathrm{Ni})_{3} \mathrm{O}_{4}$ high entropy oxide (HEO) for use in $\mathrm{Li}$-ion batteries.

Structural and chemical characterization of these high entropy materials were carried out using aberration corrected STEM, energy-dispersive X-ray spectroscopy (EDS), and X-ray diffraction (XRD) confirmed single phase spinel crystal structure of high entropy solid solution and homogenous distribution of compositional elements (Figure 1). High angle annular dark field imaging (HAADF), which is a Zcontrast imaging technique and can resolve the transition metal atoms, has been utilized in this research (Figure 2).

This research focuses on shedding light to the structural chemistry, interactions among multiple metal cations and complex electrochemical reactions of this new materials during lithiation and de-lithiation science obtained via powerful in-situ TEM. We explored the chemical and electrochemical reactions, structural stability, phase transformation of HEO during charging and discharging, to elucidate more indepth knowledge about underlying mechanisms and accurate model for atomic structure engineering of entropy stabilization to design electrochemistry. In-situ STEM-EELS studies showed that each individual metal cations of HEO has critical role in the subsequent electrochemical properties. we found transition metal HEO undergos reversible conversion reaction mechanism via reducing active metal ions during lithiation, while $\mathrm{Mg}$ provides the structural stabilization role of nanoparticles during redox reactions [4]. 


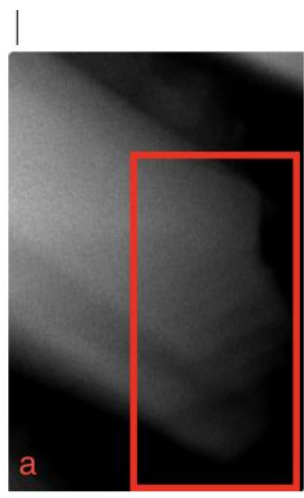

Ni K $\alpha 1$

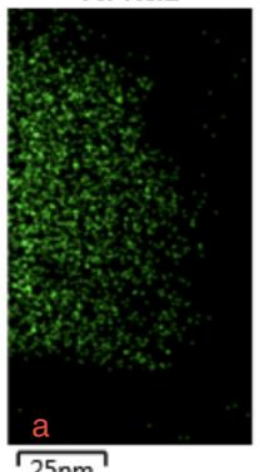

$\longdiv { 2 5 \mathrm { nm } }$
$\mathrm{Fe} \mathrm{K} \alpha 1$

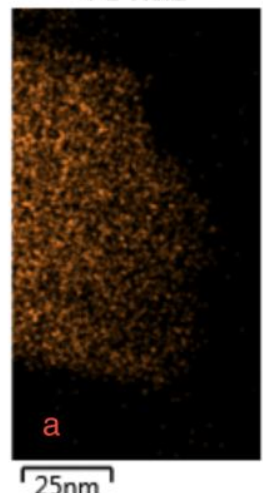

$\mathrm{O} K \alpha 1$

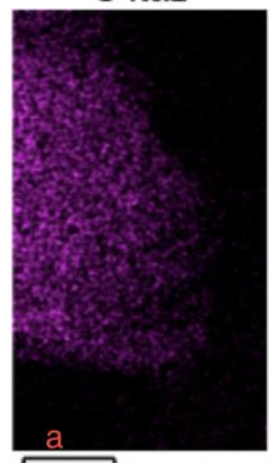

$\sqrt{25 \mathrm{~nm}}$
$\mathrm{Cu} \mathrm{K \alpha 1}$

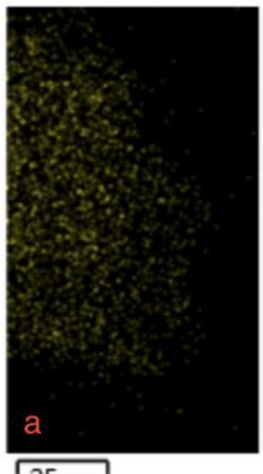

$\sqrt{25 \mathrm{~nm}}$
$\mathrm{Mn} \mathrm{K} \alpha 1$

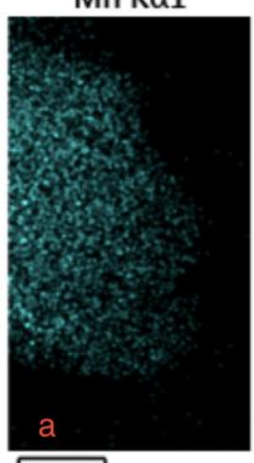

$\longdiv { 2 5 \mathrm { nm } }$
$\mathrm{Mg} \mathrm{K \alpha 1 \_ 2}$
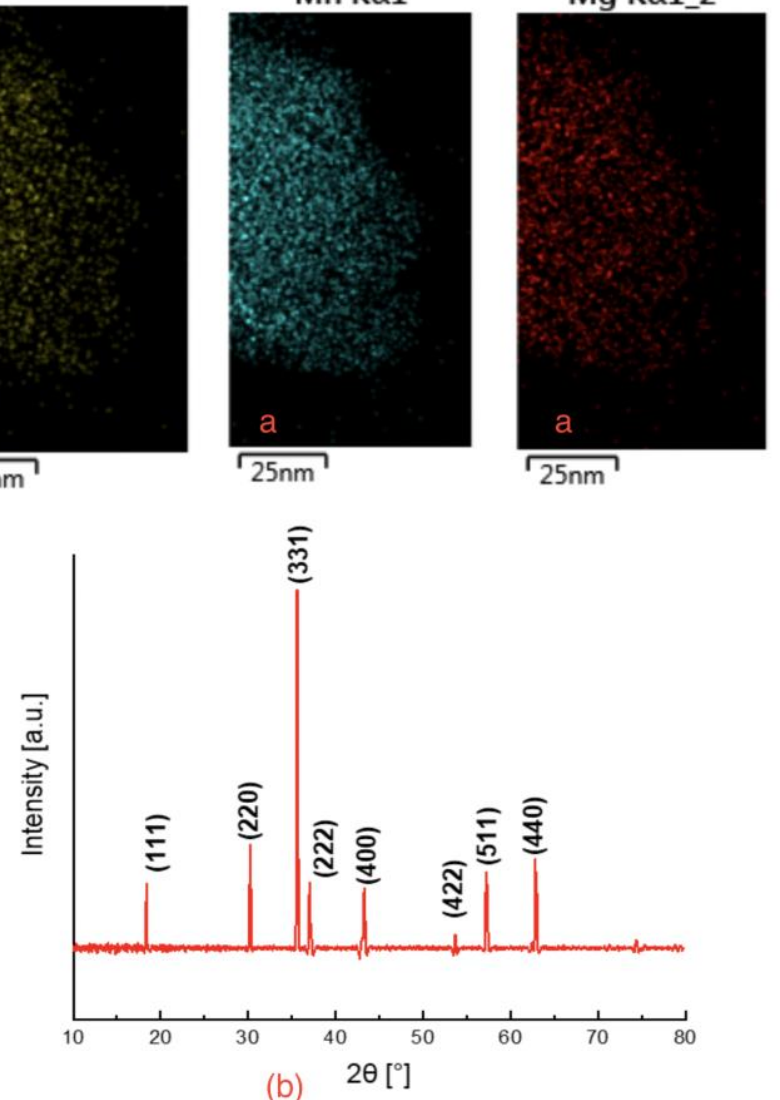

Figure 1. (a) EDS elemental mapping images of $\mathrm{Fe}, \mathrm{Cu}, \mathrm{Mg}, \mathrm{Mn}, \mathrm{Ni}$ and $\mathrm{O}$ in the $\mathrm{HEO}$, (b) XRD diffraction pattern of the HEO shows well indexed planes of the spinel (cubic Fd3m space group) structure.
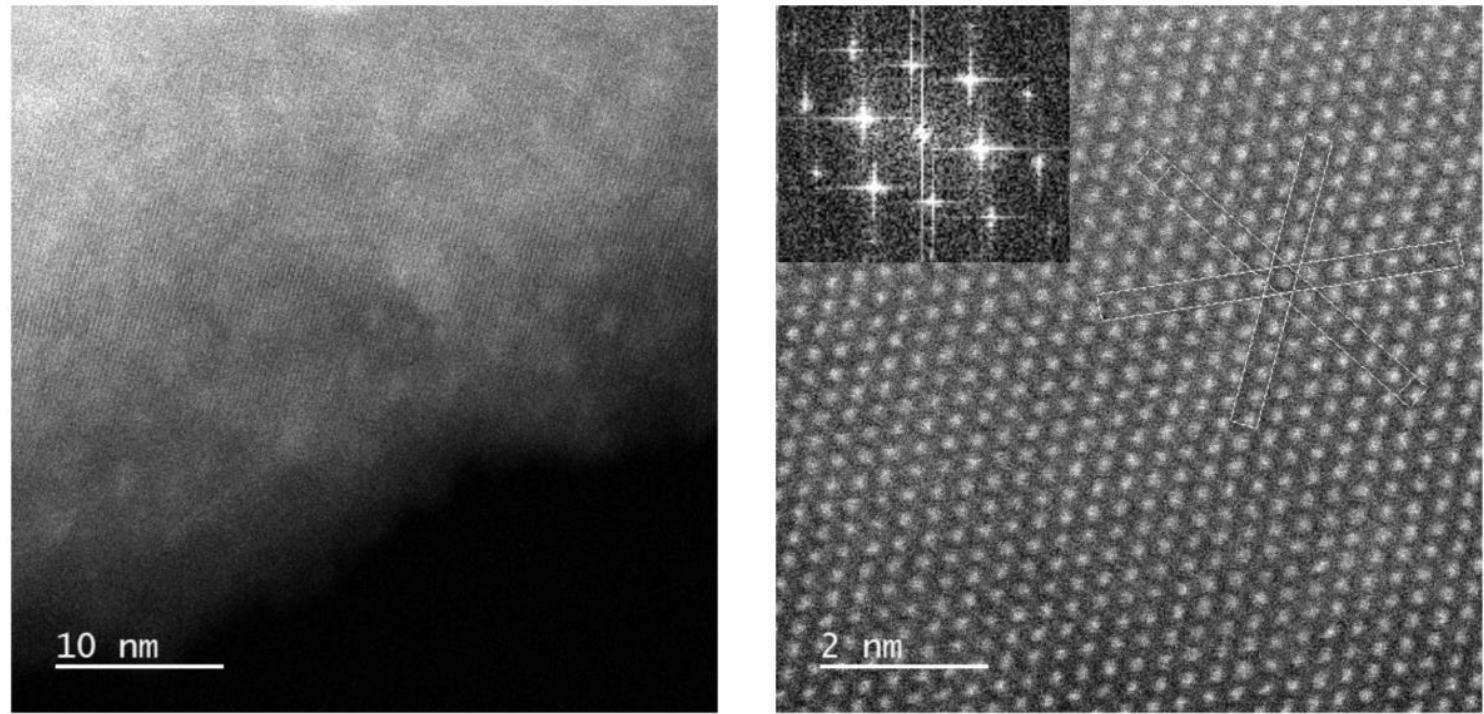

Figure 2. HAADF-STEM images of HEO (Inset is the FFT of the HEO).

References

[1] E. P. George et al., High-entropy alloys. Nature Reviews Materials, 4 (2019), p. 515-534. 
[2] C. Oses. et al., High-entropy ceramics. Nature Reviews Materials, (2020), p. 1-15.

[3] A. Sarkar et al., High-Entropy Oxides: Fundamental Aspects and Electrochemical Properties. Advanced Materials, 31(2019), p. 1806236.

[4] R. Shahbazian-Yassar acknowledges the financial support from NSF-DMR 1805938. 